\title{
Correction to: Making large-scale surgical trials possible: collaboration and the role of surgical trainees
}

\author{
Marcus Jepson ${ }^{*}$, Michelle Lazaroo², Samir Pathak ${ }^{3}$, Natalie Blencowe ${ }^{3,4}$, Jane Collingwood ${ }^{3}$, Madeleine Clout ${ }^{2}$, \\ Giles Toogood ${ }^{5}$, Jane Blazeby ${ }^{6}$ and on behalf of the Sunflower Study Executive Group
}

\section{Correction to: Trials 22, 567 (2021)}

https://doi.org/10.1186/s13063-021-05536-7

Following the publication of the original article [1], we were notified of a missing statement in the Funding section.

- Originally published Funding section read:

The study is also supported by the Royal College of Surgeons Surgical Trials Centre in Bristol. NB and JB are supported by the NIHR Bristol and Weston Biomedical Research Centre. (etc.....)

- The Funding section should actually read:

This work is supported by the National Institute for Health Research (NIHR) Health Technology Assessment Programme (Grant Ref: 16/142/04). The study is also supported by the Royal College of Surgeons Surgical Trials Centre in Bristol. (Etc...)

The original article has been corrected.

\begin{abstract}
Author details
${ }^{1}$ QuinteT Research Group, Population Health Sciences, Bristol Medical School, Canynge Hall, 39 Whatley Road, Bristol BS8 2PS, UK. ${ }^{2}$ Clinical Trials and Evaluation Unit, University of Bristol Faculty of Medical and Veterinary Sciences, Bristol, UK. ${ }^{3}$ Bristol Centre for Surgical Research, Population Health Sciences, Bristol Medical School, Canynge Hall, 39 Whatley Road, Bristol BS8 2PS, UK. ${ }^{4}$ University Hospitals Bristol and Weston NHS Foundation Trust, Trust
\end{abstract}

The original article can be found online at https://doi.org/10.1186/s13063021-05536-7.

* Correspondence: Marcus.jepson@bristol.ac.uk

'QuinteT Research Group, Population Health Sciences, Bristol Medical School, Canynge Hall, 39 Whatley Road, Bristol BS8 2PS, UK

Full list of author information is available at the end of the article
Headquarters, Marlborough St, Bristol BS1 3NU, UK. ${ }^{5}$ Department of Hepatobiliary and Transplantation Surgery, St James's University Hospital, Leeds LS9 7TF, UK. ${ }^{6}$ NIHR Biomedical Research Centre Bristol, University Hospitals Bristol and Weston NHS Foundation Trust, University of Bristol, Oakfield House, Oakfield Grove, Bristol BS8 2BN, UK.

Published online: 13 September 2021

\section{Reference}

1. Jepson, et al. Making large-scale surgical trials possible: collaboration and the role of surgical trainees. Trials. 2021;22:567. https://doi.org/10.1186/s13 063-021-05536-7.

(- The Author(s). 2021 Open Access This article is licensed under a Creative Commons Attribution 4.0 International License, which permits use, sharing, adaptation, distribution and reproduction in any medium or format, as long as you give appropriate credit to the original author(s) and the source, provide a link to the Creative Commons licence, and indicate if changes were made. The images or other third party material in this article are included in the article's Creative Commons licence, unless indicated otherwise in a credit line to the material. If material is not included in the article's Creative Commons licence and your intended use is not permitted by statutory regulation or exceeds the permitted use, you will need to obtain permission directly from the copyright holder. To view a copy of this licence, visit http://creativecommons.org/licenses/by/4.0/. The Creative Commons Public Domain Dedication waiver (http://creativecommons.org/publicdomain/zero/1.0/) applies to the data made available in this article, unless otherwise stated in a credit line to the data. 